Os grandes eventos e a cultura em Portugal: sobre os Impactos culturais da Expo'98 e os Públicos do Porto 2001

\title{
Claudino Ferreira
}

\section{(2) OpenEdition Journals}

Edição electrónica

URL: http://journals.openedition.org/rccs/1219

DOI: $10.4000 /$ rccs. 1219

ISSN: 2182-7435

Editora

Centro de Estudos Sociais da Universidade de Coimbra

Edição impressa

Data de publição: 1 dezembro 2003

Paginação: 135-138

ISSN: 0254-1106

Refêrencia eletrónica

Claudino Ferreira, "Os grandes eventos e a cultura em Portugal: sobre os Impactos culturais da Expo'98 e os Públicos do Porto 2001 », Revista Crítica de Ciências Sociais [Online], 67 | 2003, posto online no dia 01 outubro 2012, consultado o 22 setembro 2020. URL : http://journals.openedition.org/rccs/ 1219 ; DOI : https://doi.org/10.4000/rccs.1219 


\section{Recensões}

Os grandes eventos e a cultura em Portugal: sobre os Impactos culturais da Expo'g8 e os Públicos do Porto 2001

Maria de Lourdes Lima dos Santos, António Firmino da Costa (coords.), Rui Telmo Gomes, Vanda Lourenço, Teresa Duarte Martinho, José Soares Neves, Idalina Conde, Impactos culturais da Expo'98. Uma análise através da imagem mediática. Lisboa: Observatório das Actividades Culturais, 1999, 286 pp.

Maria de Lourdes Lima dos Santos (coord.), Rui Telmo Gomes, José Soares Neves, Maria João Lima, Vanda Lourenço, Teresa Duarte Martinho, Jorge Alves dos Santos, Públicos do Porto 2001. Lisboa: Observatório das Actividades Culturais, 2002, 342 pp.

Os livros em discussão sintetizam os resultados de duas investigações conduzidas pelo Observatório das Actividades Culturais, instituição que tem vindo a desempenhar um papel decisivo na produção de informação e no desenvolvimento da pesquisa sociológica sobre a cultura em Portugal. Os dois trabalhos representam um importante contributo para a compreensão do significado e das implicações culturais dos dois grandes eventos recentemente realizados no nosso país: a Expo'98 e a Porto 2001. Em ambos os casos, uma linha de força fundamental atravessa o esforço analítico desenvolvido: a ponderação dos efeitos decorrentes do carácter a vários títulos excepcional dos eventos. Esses efeitos são no entanto equacionados nos dois livros em planos distintos: no caso da Expo'98 adopta-se uma perspectiva mais abrangente, explorando os diversos domínios em que se fizeram sentir os impactos culturais do evento; no caso da Porto 2001 procura-se avaliar o "efeito de evento" sobre a natureza e as modalidades de relação com a cultura reveladas pelos públicos da sua programação.
O estudo sobre a Expo'98 orienta-se claramente por uma perspectiva de análise de impactos, que é enunciada desde logo no título do livro. Utilizando como principal fonte de informação materiais de imprensa, complementados com documentação produzida pela própria organização da Expo'98, o livro descreve e analisa as estratégias e as lógicas de programação do evento e equaciona os impactos culturais gerados pela sua realização num extenso conjunto de planos: na exposição mediática da cultura; na criação e na oferta cultural e artística; na inserção da cidade, dos criadores e dos públicos nacionais nos circuitos culturais internacionalizados; na sensibilização, mobilização e formação de públicos para a cultura, a ciência, a tecnologia, as questões ecológicas; na relação dos cidadãos com um espaço público onde confluem as lógicas da cultura, do lazer e do turismo; nas representações do país e da identidade nacional; no debate público sobre todos estes aspectos.

$\mathrm{Na}$ forma como estes vários temas são abordados, há dois aspectos que devem ser realçados. O primeiro refere-se ao modo como 
a análise se mantém atenta aos múltiplos e muitas vezes contraditórios efeitos decorrentes da complexidade e da heterogeneidade das lógicas e dimensões que se cruzam no evento e que, como se argumenta nos dois capítulos iniciais, definem a sua singularidade. Uma das principais constatações que, deste ponto de vista, resultam do estudo é precisamente a diversidade dos impactos da Exposição Mundial e também, em muitas circunstâncias, a sua ambiguidade. Outra constatação, particularmente sugestiva, remete para o facto de uma parte dos efeitos culturais identificados radicarem nas múltiplas contaminações potenciadas pela convivência, por vezes tensa, entre diversos géneros, formas e concepções culturais e entre a cultura e as outras dimensões do evento (a urbanística, a tecnológica, a turística, a convivial e festiva, a política, a ritualística, a representacional, a mediática). Em todo o caso, é de assinalar a atitude interrogativa e problematizante dos autores sobre o real alcance e a natureza dos impactos que vão sendo analisados e sobre o modo como eles se articulam com as dinâmicas em curso na esfera cultural em Portugal.

O segundo aspecto que pretendo salientar prende-se com a maneira como, embora de forma desigual nos vários capítulos, o balanço dos resultados do evento vai sendo acompanhado de referências aos debates e às controvérsias geradas pelas suas opções programáticas. Este aspecto remete para uma dimensão habitualmente pouco valorizada, mas igualmente relevante dos impactos do evento: a abertura de um amplo espaço de debate público em torno, não apenas, mas também, das questões da cultura e da política cultural. Deste ponto de vista, o último Capítulo, dedicado à sistematização das diversas avaliações que a Expo'98 suscitou, nomeadamente entre os comentadores na imprensa, parece menos conseguido, em virtude do seu cariz essencialmente descritivo. Uma abordagem mais argumentativa e problematizante sobre a conflitualidade simbólica, programática e política gerada pela Expo'98 no espaço público, e sobretudo no espaço da impren$\mathrm{sa}$, teria permitido aprofundar as pistas de discussão que a esse respeito vão sendo sugeridas ao longo do livro. Este é talvez um domínio em que o estudo foi menos ambicioso na exploração da principal fonte de informação utilizada, os materiais de imprensa, que, como afirmam os autores, implicaram tanto limitações como potencialidades para o alcance da pesquisa. Sendo certo que ao longo do livro os limites são respeitados e controlados e as potencialidades amplamente demonstradas (por exemplo na atenção dedicada aos efeitos de mediatização associados ao evento), sente-se, porém, a ausência de uma discussão mais aprofundada sobre os processos, as lógicas e os critérios subjacentes à produção de informação jornalística sobre o evento, que a estratégia metodológica adoptada justificaria.

O livro sobre a Porto 2001 apresenta os resultados de um inquérito realizado aos públicos da programação da Capital Europeia da Cultura e caracteriza os seus comportamentos, atitudes e opiniões face ao evento e às iniciativas em que participaram, assim como o perfil das suas práticas culturais fora do evento. Duas linhas de questionamento principais conduzem a análise. A primeira explora a tensão entre a selectividade e a heterogeneidade que os dados revelam acerca da composição social dos públicos e dos seus perfis de práticas culturais. A segunda remete para aquilo que os autores designam de "efeito Porto 2001". No que se refere à primeira linha, a caracterização sociográfica dos públicos dá conta da fortíssima predominância de população jovem e muito qualificada escolar e profissionalmente, traços que reproduzem na Porto 2001 os efeitos de selectividade que vêm sendo notados na generalidade 
dos estudos sobre os públicos da cultura em Portugal. Neste panorama geral de forte selectividade, no entanto, a análise permite aos autores identificar também elementos de heterogeneidade. Essa heterogeneidade manifesta-se, desde logo, na expressão diferenciada que aqueles três critérios de selectividade assumem na composição dos públicos específicos de cada uma das áreas de programação (música, artes plásticas, animação da cidade, etc.). Revela-se ainda, de forma mais nítida, na tipologia dos públicos apresentada no último capítulo e construída com base numa análise de clusters em que se retiveram indicadores relativos aos perfis sociais e aos padrões de práticas culturais e de lazer dos inquiridos. Seis segmentos de públicos são distinguidos: os "cultivados", os "liminares", os "especializados", os "retraídos", os "displicentes", os "recatados". Esta tipologia ilustra tanto os efeitos diferenciadores da idade e das qualificações escolares e profissionais, como a pluralidade das modalidades de relação com a cultura que se observam entre os consumidores culturais regulares. Sem que isso minimize a consistência e as virtualidades interpretativas da análise desenvolvida neste capítulo, ela é no entanto muito marcada por um traço persistente nos estudos sobre as práticas culturais entre nós: o pressuposto do praticante cumulativo e intensivo ("omnívoro", na expressão de R. Peterson) como modelo ideal de consumidor cultural e como referencial para as políticas de alargamento social do acesso à cultura.

No âmbito da segunda linha de questionamento, o estudo procura ponderar o efeito que o carácter excepcional e mediático da Capital Europeia da Cultura poderá ter exercido quer sob a atracção de franjas da população menos propensas à prática cultural, quer sob as formas de relação com a cultura que se expressaram no quadro da própria programação da Porto 2001. Ao longo do texto, esta questão é equacionada fundamentalmente tendo em vista a sondagem dos efeitos do evento na promoção de dinâmicas de diversificação e alargamento social dos públicos da cultura. Os autores encontram sinais de efeitos potencialmente propiciadores desse alargamento, por exemplo, no carácter socialmente mais heterogéneo dos públicos captados por algumas instituições e áreas de programação, na participação de segmentos de públicos que, fora do contexto do evento, se revelam muito alheados da prática cultural e no forte envolvimento da população escolar. A interpretação desses sinais é justificadamente contida, em vista não só da forte selectividade social atrás referida, mas também do outro lado do "efeito Porto 2001": o carácter efémero da mobilização de novos públicos conseguida no quadro do evento. Deve-se notar, a este respeito, que a ponderação desses efeitos contraditórios teria ganho com um maior aprofundamento da análise comparada entre os padrões das práticas culturais e de lazer dos inquiridos e as suas formas de participação no evento, explorando por exemplo o cruzamento destas últimas com a tipologia de públicos apresentada no capítulo final. Esse aprofundamento permitiria igualmente ilustrar com maior detalhe um dos aspectos mais sugestivos e interessantes do estudo: a atenção que dedica à heterogeneidade das opções e das combinações de actividades culturais que marca a relação dos públicos com a programação do evento. Reflecte-se talvez aqui o aspecto menos aliciante do livro: a sua estrutura, organizada em grande proximidade com o formato do questionário e com um pendor muito descritivo. Embora tenha a virtude de proporcionar ao leitor melhor acesso a um manancial de informação original e a um detalhe analítico de valor inestimável, essa estrutura prejudica a sistematização e, nalguns casos, o desenvolvimento, das interessantes 
pistas interpretativas e linhas de problematização que vão sendo enunciadas ao longo do texto.

Em suma, os dois trabalhos reúnem um volume de informação e um conjunto de reflexões que os tornam referências indispensáveis para a compreensão dos eventos em causa. Além disso, trazem também contributos relevantes para o debate mais amplo sobre a natureza e as implicações das políticas culturais e urbanas que se apoiam neste género de realizações, um debate que urge aprofundar e enriquecer com um diálogo mais intenso com o muito que, neste domínio, vem sendo feito a nível internacional.

\section{Claudino Ferreira}

\section{Josep Ballart Hernández e Jordi Juan i Tresseras, Gestión del património cultural. Barcelona: Ariel, 2001, 238 pp.}

O livro de Josep Hernández e Jordi Tresseras emerge do dilema que, cada vez mais, se coloca à sociedade, em geral, e às administrações e agentes locais, em particular. Face a um volume crescente de bens que adquirem o estatuto de património cultural, como encontrar formas de gestão desses bens que assentem num equilíbrio entre conservação e uso? Por outras palavras, como gerir o património cultural de modo a que os bens que o constituem não sejam nem um mero sorvedouro de dinheiros públicos nem mercadorias que, embora rentáveis, são incapazes de funcionar como elemento de confronto do passado com o presente da sociedade e de, nessa medida, permitir reflectir sobre o devir?

Tal como noutros livros anteriormente recenseados (La gestion du patrimoine culturel - in Revista Crítica de Ciências Sociais, 56: 153-155 - e La gestión y el gestor del patrimonio cultural - in Contextos de Sociologia, 2: 47-51), o ponto de partida dos autores deste livro radica no argumento que são igualmente legítimos, quer os esforços de patrimonialização que assentam nas emoções e na contemplação estética dos bens que o passado legou, quer as acções cuja preocupação reside em definir usos que tornem rentáveis os investimentos feitos na preservação desses bens. Garantir uma certa harmonia entre estes dois desideratos é o desafio da gestão moderna do patrimó- nio que se apresenta como o conjunto de acções programadas visando garantir uma conservação óptima dos bens patrimoniais e um uso desses bens que se adeqúe às exigências sociais contemporâneas (p. 15). Os nove capítulos que dão corpo ao livro, balançando entre um carácter de cariz mais didáctico ou de natureza mais ensaística, cobrem matérias como a conceptualização do património, o lugar do património e dos museus na História, o papel do património e dos museus no presente, o enquadramento institucional e legal do património, os modelos de gestão das organizações que lidam com o património, as políticas culturais de âmbito patrimonialista e os usos sociais que lhes subjazem, a difusão do património e, por fim, a relação entre património e turismo.

Face à literatura publicada neste domínio disciplinar (cf. Contextos de Sociologia, 2: 47-51), os pontos mais apelativos deste livro que entendemos destacar prendem-se com a análise da profissionalização dos gestores do património e da ética profissional que os orienta (p. 112), com a questão dos recursos e do financiamento de que as organizações gestoras do património podem dispor (p. 123) e com a abordagem da relação entre património e turismo (p. 201).

Trata-se de um livro que, relativamente à gestão do património, permite identificar 
e caracterizar genericamente os agentes multilaterais mais relevantes, os principais marcos legais de âmbito internacional e os modelos de gestão e de financiamento que circulam globalmente. Além disso, potenciando estudos mais analíticos neste campo disciplinar, o livro fornece um conjunto de tipologias diversas que possibilita, por exemplo, a identificação de tipos de actores envolvidos na selecção de património e de tipos de usos que justificam essa selecção (p. 18), a enumeração das funções que cabem às instituições gestoras (p. 23), a caracterização dos tipos de organizações gestoras (pp. 84, 86 e 119), a referenciação de dimensões das condutas éticas dos profissionais da gestão do património (p. 117) ou a especificação de tipos de públicos a que se destinam os bens patrimoniais e a utilidade desses bens para cada um dos diferentes tipos (p. 192).

Outra das mais-valias deste livro, constituindo um vector cujo aprofundamento se justificaria em várias das temáticas abordadas e que poderia conferir ao texto uma vertente mais analítica e ilustrativa, tem a ver com a apresentação de algumas iniciativas que, no campo das políticas culturais e patrimoniais, têm sido desenvolvidas na cidade onde os autores trabalham na sua qualidade de docentes e investigadores universitários. Tanto mais que Barcelona, a cidade em causa, tem sido adoptada como "case study" por excelência no domínio das matérias que o livro trata.

Entre os aspectos do livro que nos merecem algumas reservas destacamos dois em particular. Um de natureza mais formal e outro que tem a ver com a definição e o modo de abordagem do objecto.

No que respeita ao primeiro aspecto, a referenciação das fontes é deficiente, na medida em que nem sempre segue o sistema autor-data e em que, no corpo do texto, faz alusão a fontes que, presumindo-se que constam das referências bibliográficas finais, não é possível identificá-las. Por exemplo, na página 125 , os autores ao dizerem que "de acordo com Lord \& Lord e outros estudos...", não explicitam qual dos dois trabalhos de B. Lord e G. Lord referidos na listagem bibliográfica final estão a citar, nem identificam os "outros estudos” a que aludem. Além disso, por vezes, os autores fazem generalizações e afirmações que, não remetendo nem para casos empíricos nem para fontes, carecem de fundamentação e de demonstração, correndo o risco de poderem ser tomadas como posições ideológicas de certas políticas patrimonialistas. É o caso, por exemplo, quando referem que "nos centros urbanos históricos a recuperação dos monumentos históricos para fins distintos dos originais deu bons resultados e contribuiu para modernizar a base económica" (p. 156).

No que respeita ao segundo aspecto, a uma conceptualização alargada de património, patente no título do livro e no primeiro capítulo, corresponde uma análise que em muitas das temáticas abordadas se limita aos museus e às novas formas de museologia. Para ultrapassar esta discrepância, os autores estabelecem uma distinção entre funções internas e funções públicas das instituições patrimoniais. Nesta distinção, deixam de fora da análise do objecto as funções de gestão eminentemente técnicas que têm a ver com tarefas administrativas internas e que exigiriam abordagens organizacionais mais detalhadas. Enquanto a análise das funções internas faz sobressair uma visão mais museológica de património, ancorada na problemática de gestão de colecções, a abordagem das funções públicas cobre temáticas que suscitam o interesse de profissionais da gestão do património que operam noutros universos que não o museal.

\section{Paulo Peixoto}




\section{Georges Banu (dir.), Les cités du théâtre d'art - de Stanislavski à Strehle. S/l: Éditions Théâtrales, 2000, 331 pp.}

Les cités du théâtre d'art - de Stanislavski à Strehler é uma obra colectiva dirigida por Georges Banu, cuja publicação resulta de uma pesquisa preliminar sobre o conceito de théâtre d'art. Esta noção serviu de base a um colóquio europeu co-organizado pela Universidade Paris III e a Académie Expérimentale des Théâtres, tendo ainda como associadas diversas instituições teatrais e de pesquisa, entre outras, o Théâtre $d u$ Rond-Point-Compagnie Marcel Maréchal, o Théâtre du Vieux-Colombier, o Piccolo Teatro di Milano, o CNRS.

A obra agrega e organiza um conjunto representativo de textos sobre práticas e estéticas que se radicam na emergência e na continuidade de um "conceituado" théâtre d'art, constituindo-se em documento incontornável de bibliografia geral pelos ricos e vivos exemplos, também de cidadania, que fornece.

As trezentas e trinta e uma páginas são agrupadas em cinco capítulos, antecedidos por dois textos iniciais, um de Giorgio Strehler ("Les quatre cités du théâtre d'art") e o segundo de Georges Banu ("Les cents ans du théâtre d'art"). Tenta-se, ao longo da obra, «reinventar» as "acções/percursos" de um théâtre d'art, nas suas fundamentais e constitutivas asserções. Como?

- Identificando várias posições e valores

(Positions) de criadores como Anatoli Smelianski, Peter Stein, Jacques Lassalle, Anatolli Vassiliev, Stéphane Braunschweig, Yannis Kokkos, e Jean-Loup Rivière;

- traçando uma possível trajectória por cidades, como Moscovo, Munique, Paris, Estocolmo, Varsóvia, Bucareste e Atenas, às quais estão associados trabalhos teatrais de referência (Repères);
- sistematizando as permanências: o carácter artesanal da produção artística, as opções de repertório, o espaço, a constituição de "escolas" de formação, as questões de ética assumidas pelos respectivos criadores e as políticas editoriais, normalmente associadas a uma acção criativa (Permanences);

- relembrando os cruzamentos, os quais remetem, sobretudo, para o Cinema, a Pintura e as Artes Decorativas (Carrefours);

- permeando as asserções mais inaugurais desta prática teatral - e do correspondente conceito - de outras contribuições, as quais se tornaram identitárias, como, por exemplo, os trabalhos desenvolvidos por Strehler, Bergman, Krejca, Chéreau, Vitez, Pasqual, e Robert Wilson (Identités).

O leitor pode ainda encontrar cópias de cartas, entrevistas, breves depoimentos, desenhos, fotografias, croquis e excertos de cadernos de encenação que tentam ilustrar um sem fim de vidas e vivências artísticas que os participantes na obra insistem em perpetuar: um "Teatro de Arte" em consonância e/ou dissonância com os exemplos históricos, fora e/ou dentro das suas cidades.

A realidade que o conceito théâtre d'art agrega e reflecte foi um viveiro inestimável de produção criativa (entre outros exemplos o do Teatro de Arte de Moscovo e o Quartel francês) e, consequentemente, de revisitação. Essa produção artística deseja-se anuladora do desperdício teatral. O "Teatro de Arte" nasce do ímpeto de fragilizar silenciando o Teatro do desperdício. Aquele teatro tem como gérmen o não-desaproveitamento. É uma actividade não-homogénea e muito menos hegemóni- 
ca. Desenvolve-se em conjunturas e territórios particulares, pretende-se e reivindica-se artística (de e com arte) evocando os seus enunciados, inscrições, gritos e murmúrios. A presente obra é um levantamento sério dessas inscrições e manifestos de um passado, ainda muito presente, de uma linguagem/construção específica, bem entendido, a teatral. Sobre a noção de théâtre d'art, da qual a obra parte, pode afirmar-se ainda que é um conceito "económico", de um teatro "da economia”. O "Teatro de Arte" tentou fazer "economia" num sistema integral das artes; procurou articular certas artes numa estratégia e vontade de interpenetração, fazendo-as interagir numa plataforma de comunicação e acção democrática, cujo intento não seria mais do que o destronar da monarquia cifrada do dito teatro comercial, armadilha sócio-espectacular, segundo os crentes e devotados ao primeiro.

Esse sim, seria, por declaração e em conformidade aos seus postulados, o Teatro que economiza e prospecciona o espaço, também arquitectónico, abrindo a sua prática a outros territórios e áreas de actuação; seria um teatro que cogita a sua existência, a sua função, os seus meios e fins, que se atribuiria uma política coadjuvante de um programa desejavelmente eficiente, ao nível interno, através da (in)formação dos seus intervenientes constitutivos e, eficaz, ao nível externo, no cumprimento de estratégias de formação de públicos e de preocupações de cidadania.

Seria e foi - tal como esta obra exemplarmente o demonstra e ilustra - um teatro que reequacionou a matriz da criação, em que os recursos são escassos, a procura incessante, não obstante, por fluxos e castas, embora a oferta, segundo os seus precursores, recorrentemente desperdiçada. A disposição dos elementos desta matriz obrigaria, ela própria, a uma economia de funções, bem como de aptidões, num estatuto de suposta equidade, sem protagonismos caprichosos, levando à supressão de toda e qualquer unidade do desnecessário e de não-excepção. Esta relação equi-estatutal de pertença viria, por ironia do implícito, a ser afagada pelo metteur en scène. Ela funcionaria como condição sine qua non e como pré-requisito de filiação à referida "democracia" inaugural, a qual, atravessada por ressonâncias de um "totalitarismo" dócil e integrador, alegadamente não exacerbado, seria legitimada e reclamada sob a, então, nova égide da autoria-criação; ou numa outra postura, a da coordenação e da interpretação de uma, anterior, essa sim, obra primária e/ou prima, bem entendido, o texto.

As possíveis entradas de leitura que a publicação aqui referida apresenta, favorecem, quer na conceptualização, quer no fenómeno conceptualizado, o movimento, a continuidade e, sobretudo, fomentam a transformação numa tentativa de reciclagem dos repertórios e das trajectórias pessoais, também, geográficas. Leia-se como proferiu Strehler: "Oui, dans le siècle, il y a quatre cités dans ce conte du théâtre d'art. Elles sont nées du pays plus vaste, contradictoire et désespéré, riche en potentialités, qu'est le théâtre. [...]. Je n'ai pas voulu être l'élève du premier [Stanislavski-Moscovo] ou du second [Copeau-Paris], du troisième [Jouvet-Florença] ou du quatrième [Brecht-Berlim], j'ai voulu qu'au Piccolo les quatre se retrouvent ensemble. Ce fut mon combat et le pari de ma vie.”. Estas dinâmicas dão prioridade a ecologias interiores no seio destes colectivos (as companhias) que as reconfiguram, propiciando uma ética e estética indispensáveis à sua concepção e entendimento. Os "gestores" desta "economia" teatral, porque os houve, estão sensibilizados para as estratégias de financiamento aplicado numa generosamente optimizada articulação entre matéria-prima, instrumentos de 
trabalho e tempo de execução criativa (na emergência, não na urgência!) do produto consumado e consumido. Como? Através de directrizes pedagógicas que passam pela instauração de objectivos de produção artística. Numa primeira instância, aquelas podem obrigar à abertura do grupo. Todavia, num tempo posterior, podem mesmo implicar, segundo algumas versões, como a de Peter Stein, o seu estreitamento e, até, a sua ruptura: "Nous ne cherchions pas seulement à jouer sur le plateau, mais aussi à faire des expériences communes en dehors du plateau, de discuter, de débattre. Il n'y a pas beaucoup de personnes de talent qui sont capables d'admettre cela. [...]. Celá a réduit le nombre de candidats et la Schaubuhne est devenue un organisme assez fermé. [...] Cette déterioration des choses de la vie d'un ensemble. Mois, je suis parti depuis douze ans."

Tanto o conceito de théâtre d'art como os exercícios/exemplos específicos que permitiram a formulação desta conceptualização desvendam o segredo deste "negócio" no sacrifício, na economia das pulsões, dos desejos e das contradições, bem como nas irreverências humanas; eles poupam por opção e metodologia. Aforra-se pela (a)mestria da penitência, a qual se reifica após confissão orientada de uma verdade física, emocional... Verdade individual, social, histórica e geográfica, mesmo circunstancial no que as suas inspirações universais possam ter de local e vice-versa: "[...] Reduta reste peu connue en dehors de la Pologne. Porquoi? 1. La position périphérique du pays et de sa culture par rapport aux grands centres de la vie culturelle, Berlin, Paris, Londres, Moscou et New York. Contrairement aux théâtres russes, connus dans le monde, les théâtres polonais ne quittaient pas le pays [...]". Deste modo o "Teatro de Arte", de cons- trutura de apoio entre a potencialização do consistentemente sublime e a resistência à prontidão banal, pretendia que, no seu exercício artesanal, se instaurasse e maximizasse a legitimidade humana, social e profissional de uma actividade: "«Ma tâche consiste à purifier la famille des artistes» déclare Stanislavski convaincu que la refonte de l'acteur comme homme doit précéder sa transformation comme artiste. «Il doit être au-dessus de la foule par son talent, son instruction et par ses autres mérites.» Et l'ensemble des décisions artistiques de Stanislavski porteront la marque de ce souhait car la vie de troupe, le travail de formation culturelle des comédiens, le prolongement de la durée des répétitions visent justement à assurer un renouveau de l'acteur autant que de ses rapports aux autres. L'école et le Studio sont les laboratoires tout désignés pour cette promotion de l'éthique individuelle et de la responsabilité." Actividade essa, até então, confiscada, à força de um poder de compra e de uma ociosidade promíscua, por uma outra elite desgovernada e esbanjadora. Só assim poderia o "Teatro de Arte" devolver, com juros e correcção artística, ao banalizado, ao trivial e ao inócuo, o sublime, o belo, o significativo, sob um modelo da interpelação sensível da obra.

As cidades e seus sistemas convidam, albergam e/ou expulsam a criação de «Arte». O Teatro cresce nestas relações de troca, ocupa e define espaços em trânsitos de parceiros detentores de diversos capitais, erguendo-se, com maior ou menor adversidade. A concepção da obra em apresentação é um genuíno exemplo escrito desta "mercância", dando várias provas de que não há, nem houve, théâtre d'art sem burgo.

\section{Berta Teixeira}

